\title{
Un Siglo de Sequías: ¿Por qué las Políticas de Agua no Desarrollaron la Región Semiárida Brasileña?
}

\author{
Catarina de Oliveira Buriti ${ }^{1}$ (D), Humberto Alves Barbosa ${ }^{2}$ (D), Franklin Javier Paredes-Trejo ${ }^{2,3}$ (D), \\ T.V. Lakshmi Kumar ${ }^{4}$, Manoj Kumar Thakur ${ }^{5}$, K. Koteswara Rao ${ }^{6}$ \\ ${ }^{1}$ Instituto Nacional do Semiárido, Campina Grande, PB, Brazil. \\ ${ }^{2}$ Laboratório de Análise e Processamento de Imagens de Satélites, \\ Universidade Federal de Alagoas, Maceió, AL, Brazil. \\ ${ }^{3}$ Universidad Nacional Experimental de los Llanos Occidentales Ezequiel Zamora, San Carlos, \\ Cojedes, Venezuela. \\ ${ }^{4}$ Department of Physics, Faculty of Engineering \& Technology, SRM University, Tamilnadu, India. \\ ${ }^{5}$ Department of Physics, Tri-Chandra Multiple Campus, Tribhuvan University, Kathmandu, Nepal. \\ ${ }^{6}$ Indian Institute of Tropical Meteorology, Ministry of Earth Sciences, Pune, India.
}

Recibido em: 2 de Febrero de 2020 - Aceptado em: 14 de Julio de 2020

\section{Resumen}

El semiárido brasileño frecuentemente se ve afectado por sequías prolongadas. Durante el período 2010-2017, la región semiárida brasileña enfrentó la "sequía del siglo", considerada la peor registrada en la historia del país. Este artículo tiene como objetivo hacer una evaluación histórica de diferentes fases de las políticas públicas implementadas en la región, con el fin de promover la convivencia con la sequía. Con base en una investigación histórica documental y el monitoreo satelital de los impactos de las sequías, se analizaron las acciones gubernamentales que contribuyeron a brindar una mayor disponibilidad de agua en la región semiárida brasileña, con énfasis en el análisis de la efectividad de la gestión del agua y los impactos de las tecnologías sociales para el almacenamiento del agua de lluvia en comunidades rurales dispersas. Los resultados de la investigación evidenciaron que las políticas implementadas a lo largo de la historia, con frecuencia en un modelo centralizado, no fueron efectivas en el desarrollo de la región. Recientemente, el acceso a las tecnologías sociales hídricas descentralizadas en las zonas rurales, están mostrando resultados positivos. Sin embargo, aún no es una realidad universal para la población que vive en la región. Por tanto, se concluye que las políticas hídricas siguen siendo insuficientes para hacer frente a los impactos de las sequías. El estudio aporta importantes lecciones históricas para la gestión del agua en la actualidad.

Palabras clave: sequía, políticas hídricas, monitoreo satelital, Semiárido brasileño.

\section{Um Século de Secas: Por que as Políticas Hídricas não Transformaram a Região Semiárida Brasileira? \\ Resumo}

O Semiárido brasileiro, com frequência, é afetado por secas prolongadas. No período 2010-2017, a região semiárida brasileira enfrentou a "Seca do Século", considerada a pior já registrada na história do País. Este artigo tem o objetivo de fazer uma avaliação histórica das várias fases de políticas hídricas, implementadas na região, com o intuito de promover a convivência com a seca. Com base em investigações históricas documentais e em monitoramento por satélites dos impactos das secas, foram analisadas as ações governamentais, que contribuíram para proporcionar uma maior disponibilidade de agua na região semiárida brasileira, com foco no estudo da efetividade da governança hídrica e nos impactos das tecnologias sociais para armazenamento de agua da chuva, em comunidades rurais difusas. Os resultados da pesquisa evidenciaram que as políticas historicamente implementadas, geralmente em um modelo centralizado, não foram efetivas para desenvolver a região. Recentemente, o acesso às tecnologias sociais hídricas descentralizadas, nas áreas rurais, tem apresentado resultados positivos. Todavia, ainda não é uma realidade universal a toda a população que vive na região. Assim, conclui-se que as políticas hídricas ainda são insuficientes para fazer frente aos impactos das secas. O estudo oferece lições históricas importantes para a governança das águas nos dias atuais.

Palavras-chave: seca, políticas hídricas, monitoramento por satélites, Semiárido brasileiro. 


\section{Introducción}

En Brasil, casi 28 millones de personas viven en la región semiárida, un $13 \%$ de la población del país (IBGE, 2010). La región semiárida brasileña tiene aproximadamente 1 millón de $\mathrm{km}^{2}$ de extensión territorial (MI, 2017), y con frecuencia se ve afectada por sequías prolongadas. En algunas zonas de la región, la sequía suele durar hasta 11 meses, en condiciones históricamente normales (Ab'saber, 1977). En el período 2010-2017, la región semiárida brasileña enfrentó la "sequía del siglo", considerada la peor registrada en la historia del país. Este evento climático mostró una intensidad, alcance y duración sin precedentes, con consecuencias devastadoras para la población (Buriti y Barbosa, 2018). Durante esta gran sequía, una profunda crisis de agua afectó a la región, pues el volumen de agua en los ríos y embalses fue extremadamente crítico. Las grandes ciudades se enfrentaron a la amenaza de un colapso en el suministro (Barbosa y Kumar, 2016; Stanke et al., 2013).

En el libro "Un siglo de sequías", los autores buscaron en la historia, lecciones para el manejo sostenible de las sequías en el semiárido brasileño; un desafío que aún persiste en la actualidad, a pesar de los avances científicos y tecnológicos en el área de monitoreo ambiental. Entre las preguntas que aborda el libro se encuentran: ¿por qué las políticas de acceso al agua, implementadas en el semiárido brasileño, durante más de un siglo, han sido incapaces de transformar la realidad social de la región? ¿Por qué las sequías siguen siendo desastres naturales, que causan un daño generalizado a la economía?

Históricamente, las políticas para convivir con la sequía se han centrado en la implementación de diversas tecnologías para el almacenamiento de agua, tales como presas, riego, perforación de pozos, proyectos de integración de cuencas hidrográficas, entre otros. A pesar de un siglo de inversión de recursos públicos para resolver la escasez de agua en el semiárido brasileño, estas políticas aún no han sido suficientes para modificar el escenario socioeconómico de la región (Buriti y Barbosa, 2018).

A partir de un extenso estudio documental, basado en imágenes satelitales climáticas y meteorológicas, los autores del libro "Un siglo de sequías" describieron las sequías ocurridas en el período 1901-2016. Al mismo tiempo, analizaron tanto las políticas implementadas durante cada uno de estos eventos de sequía, como la capacidad de respuesta gubernamental a las consecuencias del fenómeno climático en la población socialmente vulnerable.

Esta evaluación histórica de las políticas de agua dio como resultado el análisis actual, sobre el cómo estas acciones contribuyeron a una mayor disponibilidad de agua en la región semiárida brasileña, centrándose en la efectividad de la gestión y las tecnologías para el almacenamiento de agua de lluvia. Es una forma de aportar lecciones para contribuir a políticas de agua más exitosas en la actualidad.

\section{Políticas de Agua en la Región Semiárida Brasileña: las Lecciones Cien Años Después}

La clasificación de la intensidad de la sequía meteorológica en la región semiárida brasileña, en el período 1901-2016, fue procesada por el Laboratorio de Análisis y Procesamiento de Imágenes Satelitales (LAPIS), basado en el Índice de Precipitación Estandarizado (SPI). El método permite monitorear el déficit de precipitación normalizado, en varias escalas de tiempo y espacio, a partir de series históricas mensuales de precipitación. El resultado del análisis se muestra en la Fig. 1.

En la Fig. 1, la severidad de la sequía se clasificó de acuerdo con la categoría del SPI mostrada en la Tabla 1.

Las políticas para las sequías en el semiárido brasileño se estructuraron en tres fases históricas distintas, de acuerdo con las soluciones políticas y tecnológicas adoptadas, en cada período. Cada una de estas fases se analiza a continuación:

\subsection{Solución hidráulica (1909-1940)}

Durante este período, ocurrió el proceso de institucionalización de las primeras políticas de agua, implementadas por el Estado brasileño, encaminadas a mitigar los impactos de las sequías. Esto se hizo a través de la Inspección de Obras Contra la Sequía (IOCS), el actual Departamento Nacional de Obras Contra la Sequía (DNOCS). En esta etapa, las políticas de agua priorizaron la construcción de grandes reservorios para almacenar el agua de las lluvias, grandes represas sobre los ríos y la perforación de pozos subterráneos.

Es un hecho que estas obras contribuyeron a la consolidación de una infraestructura de almacenamiento de agua, hasta aquel momento inexistente en la región. Sin embargo, las acciones fueron insuficientes para transformar la forma en que la población vivió con las sequías. Las obras hidráulicas se concentraron en las propiedades de los grandes productores rurales, favorecidos por las elites políticas de la región. Como consecuencia, la mayoría de la población seguía siendo vulnerable y dependiente de la ayuda gubernamental, para enfrentar la sequía; un evento climático que solía tomar una proporción de calamidad (Furtado, 1998; Silva, 2006).

\subsection{Políticas de desarrollo económico (1950-1980)}

En esta fase, destaca la influencia del economista brasileño Celso Furtado en la implementación de un proyecto político de desarrollo en el semiárido brasileño, a través de la Superintendencia de Desarrollo para el Noreste (SUDENE).

Furtado propuso un proyecto de industrialización de la región, con democratización del acceso al agua y la tierra, de manera socialmente justa. Sin embargo, muchas contradicciones marcaron la época, así como obstáculos en contra de este proyecto de transformación, que cierta- 


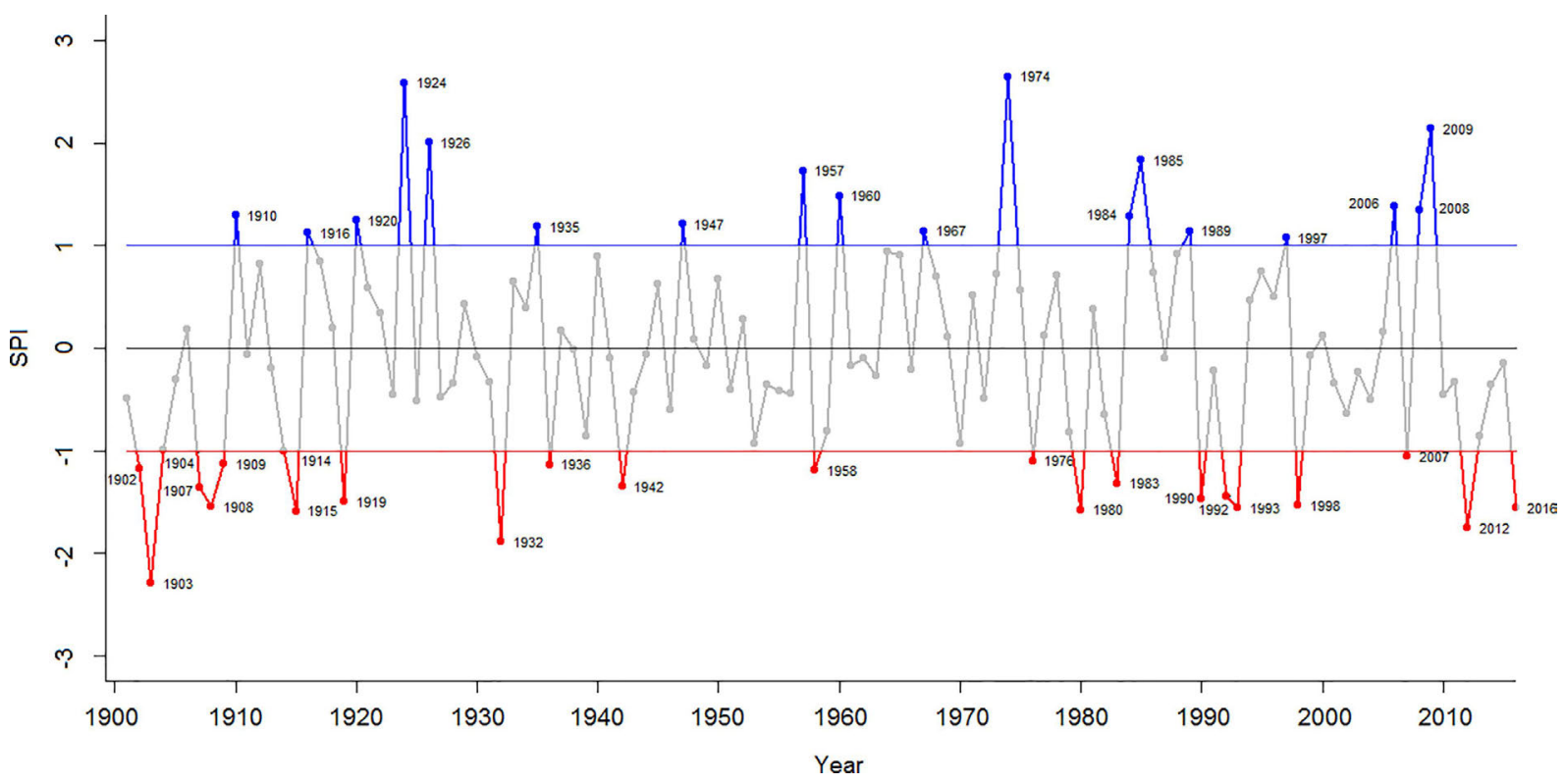

Figura 1 - Índice de precipitación mensual estandarizado, procesado anualmente, entre febrero y mayo, durante el periodo 1901-2016. Fuente: LAPIS, 2016.

Tabla 1 - Clasificación de las sequías, de acuerdo con el Índice de Precipitación Estandarizada.

\begin{tabular}{llll}
\hline \multicolumn{1}{c}{ Categoría } & \multicolumn{1}{c}{ Posibles impactos } & SPI \\
\hline $\begin{array}{l}\text { Condición normal de } \\
\text { sequía }\end{array}$ & Condición normal de precipitación. & 0 a -0.5 \\
$\begin{array}{l}\text { Condición anormal de } \\
\text { sequía }\end{array}$ & $\begin{array}{l}\text { Inicio de sequía, periodo corto en que se marchitan lentamente los cultivos, plantaciones y pastos; el riesgo de } \\
\text { incendio es incipiente; escasez de agua incipiente; los pastizales y cultivos no logran recuperarse totalmente. }\end{array}$ & -0.5 a -0.8 \\
Sequía moderada & $\begin{array}{l}\text { Los cultivos y pastizales manifiestan algunos daños; riesgo de incendio moderadamente alto; los ríos, embalses y } \\
\text { pozos presentan un nivel de agua bajo; escasez hídrica inminente, lo que implica la necesidad de conservar el agua. }\end{array}$ & -0.8 a -1.3 \\
Sequía severa & $\begin{array}{l}\text { Posible pérdida de cultivos y pastizales; riesgo de incendio alto; escasez de agua generalizada, con restricciones en } \\
\text { el uso del agua. }\end{array}$ & -1.3 a -1.6 \\
Sequía extrema & $\begin{array}{l}\text { Mayor pérdida de cultivos y pastizales; peligro extremo de incendios; estrictas restricciones en el uso del agua. } \\
\text { Sequía excepcional }\end{array}$ & $\begin{array}{l}\text { Pérdida de cultivos/ pastizales excepcional y generalizada; riesgo inminente de incendio; escasez hídrica en repre- } \\
\text { sas, ríos y pozos; creación de un estado de emergencia. }\end{array}$ & -2.0 a a -2.0 \\
\end{tabular}

Fuente: National Drought Mitigation Center (2006).

mente, no interesó a los grupos de poder político y económico en la región (Furtado, 1959).

\subsection{Políticas de desarrollo sostenible (1990-2016)}

Esta fase tuvo como marco legal el establecimiento de la Política Nacional de Recursos Hídricos (Ley n. 9.433/97), considerada una de las leyes de agua más democráticas del mundo, pues propuso un modelo de gestión de agua sostenible, compartido, descentralizado y participativo.

Las principales características de las políticas de agua de las fases anteriores fueron su carácter centralizado, concentrado y vertical, desde la planificación gubernamental hasta su implementación. Fue solo en la década de 1990 que hubo un intento exitoso de descentralizar las políticas del agua, con la participación de la sociedad civil. Este tema será discutido más adelante.

\section{3. ¿Crisis del agua o falta de gobernanza?}

En 2012, alrededor de 5 millones de personas se vieron directamente afectadas por la sequía en la región semiárida. Casi todos los 1.135 municipios, que luego formaban la región, decretaron una emergencia debido a los efectos del desastre climático. Algunos de estos municipios fueron reconocidos más de una vez en esta condición (MI, 2016).

Los impactos de la "sequía del siglo" afectaron directamente la economía nacional, especialmente la población de las metrópolis, donde ocurrió una gran reducción en la oferta de productos y un aumento en los precios de los alimentos (Stanke et al., 2013).

Esta región tiene recursos hídricos limitados, lo que hace imposible satisfacer las principales demandas de agua del sector agrícola, la principal fuente de la economía regio- 
nal (Azevedo et al., 2018). Este escenario hace que la región semiárida brasileña sea altamente vulnerable a la variabilidad climática, particularmente a las sequías (Marengo y Bernasconi, 2015).

Las imágenes satelitales (Figs. 2 y 3 ) de la cubierta de vegetación semiárida brasileña muestran los impactos de la sequía en la región cada año:

Ante esta reciente crisis del agua en la región, poco se hizo en términos de políticas públicas, con el objetivo de cambiar la cultura del uso irracional y el desperdicio de agua, a través de la educación ambiental de la población. También faltaron acciones consistentes para promover el reciclaje y la desalinización del agua, la expansión de la infraestructura de agua de la región y el fortalecimiento institucional de la gestión (Letras Ambientais, 2020).

En el libro "Un siglo de sequías", la crisis del agua se explica más como un problema de gobernanza que de escasez. Las instituciones involucradas en la gestión del agua en Brasil aún no están lo suficientemente preparadas para aplicar los instrumentos previstos en la legislación. La gestión eficiente de los recursos hídricos puede promover impactos positivos en la seguridad hídrica de la población y el sector productivo.

Los comités de cuencas fluviales siguen siendo foros marcados por desigualdades de poder político, económico y de conocimiento. La sociedad civil no está adecuadamente preparada para participar en el proceso de toma de decisiones políticas sobre el agua. Los gobiernos, por otro lado, no parecen estar dispuestos a renunciar a su control centralizado (Abers et al., 2009).

Esta realidad no solo se da en Brasil. Al enfatizar las particularidades de cada región, la gestión eficiente del agua es un concepto complejo y desafiante en otros países.

\section{Participación de la sociedad civil en el proceso de democratización del acceso al agua}

A partir de la década de 1990, la sociedad civil comenzó a participar activamente en la formulación de políticas adaptadas a la región semiárida brasileña, especialmente dirigidas a la convivencia con las sequías. Los programas del gobierno federal: "Un millón de cisternas" y "Una tierra y dos aguas" se destacan aquí. Estas acciones consistieron en la implementación de tecnologías sociales para el almacenamiento del agua, a fin de satisfacer las demandas de la población rural difusa (Gomes y Heller, 2016).

La participación social en el proceso de gobernanza, prevista en la legislación actual sobre el agua del país, se evaluó como una condición fundamental para la promoción del uso eficiente y democrático del agua (Watanabe et al., 2014). La gestión compartida permite a los distintos usuarios actuar de forma preventiva en la planificación de medidas para adaptarse a las sequías.

En el libro "Un siglo de sequías", los grupos sociales específicos de los Cariris, estado de Paraíba, microrregiones más secos de Brasil, se apropiaron del derecho a participar, con el objetivo de promover la gobernabilidad democrática del agua, en el marco de los comités de cuencas hidrográficas.

Es importante identificar los avances en la descentralización de estas políticas de acceso al agua, con base en la participación de la sociedad civil (Baqueiro, 2016; Butler y Adamowski, 2015). Estas tecnologías sociales del agua, implementadas con el apoyo de las organizaciones sociales, de la región semiárida brasileña, han tenido importantes impactos en el acceso al agua en la región. Sin embargo, aún existen muchos desafíos para la universalización del acceso a estas tecnologías sociales del agua, especialmente en las zonas rurales, a fin de adaptar
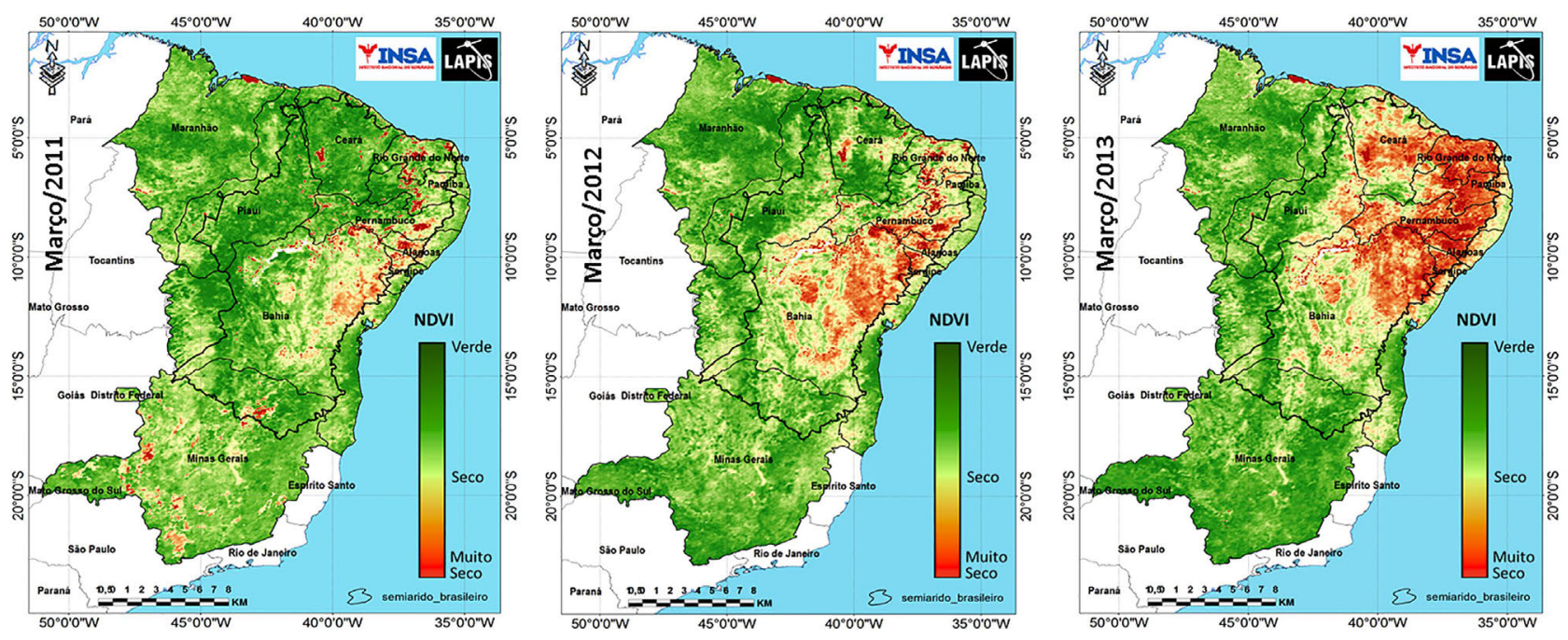

Figura 2 - Monitoreo satelital de la cubierta vegetal semiárida brasileña (2011-2013). Fuente: Buriti y Barbosa (2018). 

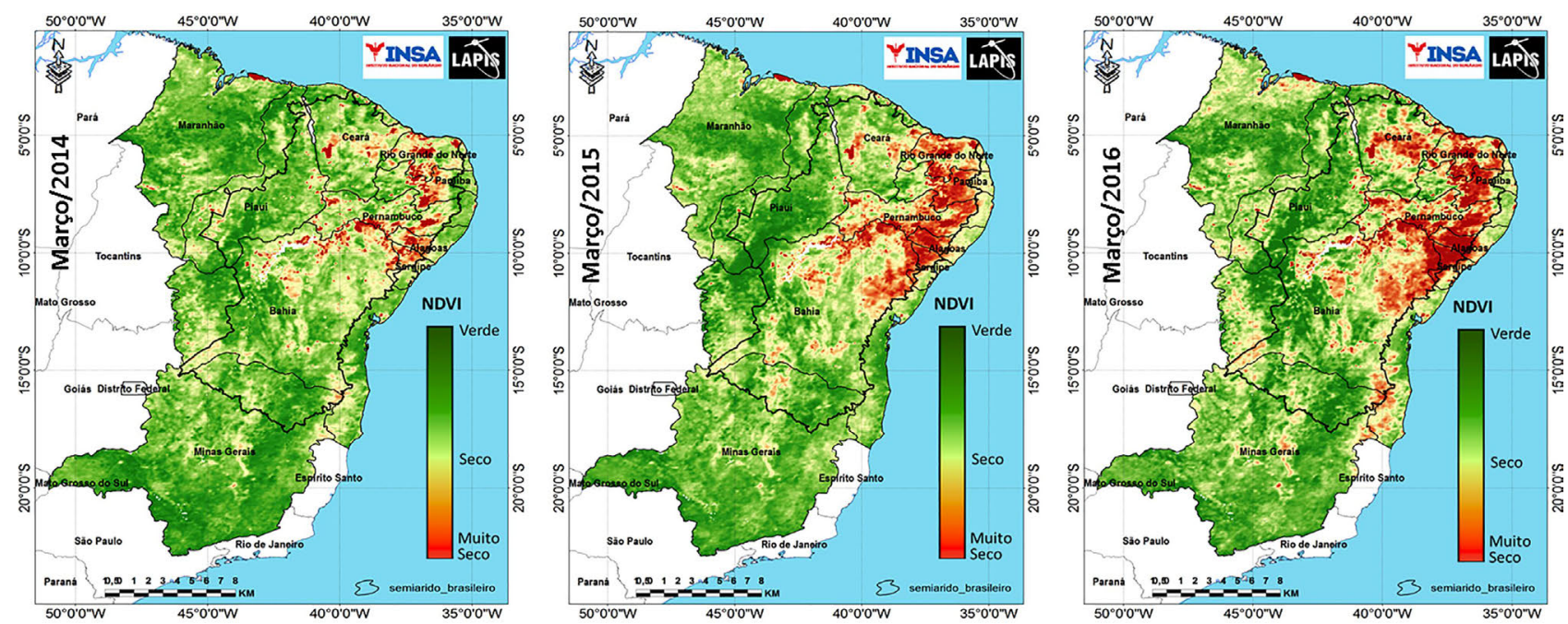

Figura 3 - Monitoreo satelital de la cubierta vegetal semiárida brasileña (2014-2016). Fuente: Buriti y Barbosa (2018).

mejor la población a las sequías. Durante la investigación, se encontró que no todas las familias de los Cariris de Paraíba recibieron tecnologías sociales para el almacenamiento de agua (Buriti y Barbosa, 2018). Esto significa que muchas familias aún enfrentan la carga diaria de transportar agua desde lugares distantes (Gomes et al., 2012).

Los programas de acceso al agua en el semiárido brasileño, basados en la implementación de tecnologías sociales, han tenido un impacto significativo en la vida de las mujeres rurales. Históricamente, fueron los principales responsables de buscar agua en fuentes distantes para mantener a la familia. Antes de P1MC, las mujeres pasaban más de 36 días por año, solo transportando agua, desde depósitos que estaban muy lejos de sus hogares (Gomes y Heller, 2016).

Con la implementación de tecnologías sociales del agua, junto con las residencias, el tiempo dedicado al transporte de agua por las mujeres se ha reducido a 12 días al año (Gomes y Heller, 2016).

El aumento de la disponibilidad de agua en las zonas rurales, a través de tecnologías sociales del agua, ha traído beneficios tangibles para las mujeres. Redujeron su trabajo y dedicaron su tiempo a actividades productivas, contribuyendo a la generación de ingresos y un mayor bienestar para sus familias (Buriti y Barbosa, 2018).

Las tecnologías sociales del agua ya han tenido un impacto importante para adaptarse a la sequía no solo en los Cariris de Paraíba. Sin embargo, en la microrregión de Cariri Oriental de Paraíba, el $62 \%$ de la población rural residente tenía acceso a la tecnología social P1MC, mientras que solo el 13\% recibió la segunda tecnología social, a través de P1 +2 . En la microrregión de Cariri Oriental de Paraíba, el $32 \%$ de la población tenía acceso a la tecnología social P1MC, mientras que solo el $0.17 \%$ tenía acceso a $\mathrm{P} 1+2$.
Los datos de la distribución de las tecnologías sociales del agua anterior muestran cómo el acceso a las políticas de tecnología social para almacenar agua de lluvia, aún no es una realidad universal para las comunidades rurales difusas de estos lugares.

Por lo tanto, el principal desafío en la actualidad es la universalización del acceso a estas tecnologías sociales del agua en el medio rural, con el objeto de proporcionar una mejor coexistencia de la población con las sequías. Las tecnologías sociales también requieren mejoras en términos de cantidad y calidad del agua almacenada.

\section{Conclusiones}

La experiencia histórica es fundamental para el diseño de estrategias de desarrollo sostenible en la región semiárida de Brasil, especialmente ante desafíos complejos, como el manejo sostenible de la sequía y la definición de los métodos más apropiados para aumentar la disponibilidad de agua.

Al estudiar las políticas del agua del pasado, los autores del libro "Un siglo de sequía" han arrojado luz sobre la planificación actual de respuestas coordinadas y sistemáticas en pro de la adaptación a la sequía y aumentar la resiliencia de la población a sus impactos. La "sequía del siglo" dejó importantes lecciones para los responsables actuales de las políticas del agua en la región semiárida brasileña. Una de ellas es la necesidad de diseñar programas que proporcionen una mayor capacidad de recuperación por parte de la población.

Entre las acciones que requieren mayores inversiones en la región semiárida brasileña se encuentran: educación ambiental, manejo sostenible de las sequías, calificación de la sociedad civil para participar en la gobernanza del agua, reutilización del agua, infraestructura de desalinización, y captación urbana de agua de llu- 
via. Además, de centrarnos en las estrategias de eficiencia de agua y energía, la conservación de los recursos naturales, la reducción de la contaminación del agua, reducir las pérdidas y el desperdicio, cobrar por el uso de los recursos hídricos y las tecnologías adaptadas a las sequías.

Las lecciones de las políticas de acceso al agua, durante más de un siglo, en la región semiárida de Brasil, resaltaron la necesidad de descentralización en la planificación e implementación de políticas de agua; priorización de las tecnologías sociales del agua que contribuyen a la democratización del acceso al agua, alcanzando especialmente a la población más vulnerable, la necesidad de universalizar el acceso a las tecnologías sociales del agua y la mejora de estos mecanismos tecnológicos, con el fin de minimizar los impactos de la sequía sobre el agua y la seguridad alimentaria de la población.

\section{Agradecimientos}

Al Conselho Nacional de Desenvolvimento Científico e Tecnológico (CNPq, processo $\left.{ }^{\circ} 154467 / 2018-9\right)$, para la Beca Postdoctoral Junior (PDJ) del primer autor. A la Coordenação de Aperfeiçoamento de Pessoal de Nível Superior (CAPES), para el financiamiento del proyecto Pró-Alertas, del Laboratório de Análise e Processamento de Imagens de Satélites (LAPIS), coordinado por el segundo autor, y por la beca post-doctoral al tercer autor, dentro del alcance del mismo proyecto Pró-Alertas.

\section{Referencias}

AB'SABER, A.N. Espaços ocupados pela expansão dos climas secos da América do Sul, por ocasião dos períodos glaciais quaternários. Paleoclimas, v. 1, n. 3, p. 1-19, 1977.

ABERS, R.N.; FORMIGA-JOHNSSON, R.M.; FRANK, B.; KECK, M.E.; LEMOS, M.C. Inclusão, deliberação e controle: três dimensões de democracia nos comitês e consórcios de bacias hidrográficas no Brasil. Ambiente \& Sociedade, v. XII, n. 1, p. 115-132, 2009.

AZEVEDO, S.C.; CARDIM, G.P.; PUGA, F.; SINGH, R.P.; SILVA, E.A. Analysis of the 2012-2016 drought in the northeast Brazil and its impacts on the Sobradinho water reservoir. Remote Sensing Letters, v. 9, n. 5, p. 438-446, 2018.

BAQUEIRO, A.H. The participation of civil society organizations in public policies in Latin America. Voluntas, v. 27, n. 1, p. 86-104, 2016.

BARBOSA, H.A.; KUMAR, T.V.L.K. Influence of rainfall variability on the vegetation dynamics over Northeastern Brazil. Journal of Arid Environments, v. 124, n. 1, p. 377-387, 2016.

BURITI, C.O.; BARBOSA, H.A. Um Século de Secas: Por Que as Políticas Hídricas Não Transformaram o Semiárido Brasileiro? Lisboa: Chiado Books, 434 p., 2018.
BUTLER, C.; ADAMOWSKI, J. Empowering marginalized communities in water resources management: addressing inequitable practices in Participatory Model Building. Journal of Environmental Management, v. 153, n. 1, p. 153-162, 2015.

FURTADO, C. A Operação Nordeste. Rio de Janeiro: ISEB, 1959.

FURTADO, C. Seca e Poder: Entrevista com Celso Furtado. São Paulo-SP: Fundação Perseu Abramo, 1998.

GOMES, U.A.F.; HELLER, L.; PENA, J. L. A national program for large scale rainwater harvesting: an individual or public responsibility? Water Resources Management, v. 26, n. 9, p. 2703-2714, 2012.

GOMES, U.A.F.; HELLER, L. Acesso à água proporcionado pelo Programa de Formação e Mobilização Social para Convivência com o Semiárido "Um Milhão de Cisternas Rurais": combate à seca ou ruptura da vulnerabilidade? Engenharia Sanitária e Ambiental, v. 21, n. 3, p. 623633, 2016

IBGE, Instituto Brasileiro de Geografia e Estatística. Censo Demográfico: Pesquisa Nacional por Amostra de Domicílios. Rio de Janeiro: IBGE, 2010.

MARENGO, J.A.; BERNASCONI, M. Regional differences in aridity/drought conditions over Northeast Brazil: present state and future projections. Climatic Change, v. 129, n. 1, p. 103-115, 2015.

MI, Ministério da Integração Nacional. Proteção e Defesa Civil: Reconhecimentos Realizados em 2016. Disponível em http://www.mi.gov.br/reconhecimentos-realizados, acesso em 24 out. 2016.

MI, Ministério da Integração Nacional. Resolução n 107/2017. Recife-PE, 27 de julho de 2017.

NDMC, National Drought Mitigation Center. Drought Monitoring. Lincoln, Estados Unidos. Disponível em https:// drought.unl.edu/, 2006.

SILVA, R.M.A. Entre o Combate à Seca e a Convivência com o Semiárido: Transições Paradigmáticas e Sustentabilidade do Desenvolvimento. Tese de Doutorado, UNB, 2006.

STANKE, C.; KERAC, M.; Prudhomme, C.; MEDLOCK, J.; MURRAY, V. Health effects of drought: a systematic review of the evidence. PLOS Currents Disasters, v. 5, n. 1, p. 1-38, 2013.

WATANABE, M.; MADRUGA, L. R. R. G.; YAMAGUCHI, C. K.; VIEIRA, A. C. P.; JENOVEVA-NETO, R. Decision making and social learning: The case of Watershed Committee of the State of Rio Grande do Sul, Brazil. Water Resources Management, v. 28, n. 11, p. 3815-3828, 2014.

\section{Recursos de Internet}

LAPIS, Laboratório de Análise e Processamento de Imagens de Satélites. Disponível em www.lapismet.com.br, 2020.

LETRAS AMBIENTAIS. Dados e Informações Ambientais. Disponível em www.letrasambientais.org.br, 2020.

License information: This is an open-access article distributed under the terms of the Creative Commons Attribution License (type CC-BY), which permits unrestricted use, distribution and reproduction in any medium, provided the original article is properly cited. 